\title{
A NON-CENTROSYMMETRIC POLYMORPH OF 5-HYDROXY-7-METHOXY-2-PHENYLCHROMAN-4-ONE
}

\author{
IVÁN BRITO ${ }^{*}$, MARIO J. SIMIRGIOTIS ${ }^{\prime}$, ANGHEL BRITO ${ }^{\prime}$, MIRIAM RODRÍGUEZ WERNER ${ }^{2}$, JORGE \\ BÓRQUEZ ${ }^{1}$, PETER WINTERHALTER ${ }^{2}$ AND ALEJANDRO CÁRDENAS ${ }^{3}$
}

\author{
${ }^{1}$ Departamento de Química, Facultad de Ciencias Básicas, Universidad de Antofagasta, Casilla 170, Antofagasta, 1240000, Chile. \\ ${ }^{2}$ Institut für Lebensmittelchemie, Technische Universität Braunschweig, Schleinitz-Str. 20, D-38106 Braunschweig, Germany. \\ ${ }^{3}$ Departamento de Física, Facultad de Ciencias Básicas, Universidad de Antofagasta, Casilla 170, Antofagasta, 1240000, Chile.
}

\begin{abstract}
The bioactive compound 5-hydroxy-7-methoxy-2-phenylchroman-4-one (pinostrobin, I), was isolated from aerial parts of Nolana ramossisima I.M. Johnst., a Chilean endemic species, using a combination of medium pressure column chromatography and high speed countercurrent liquid-liquid chromatography (HSCCC). The compound crystallized as a non-centrosymmetric polymorph in the orthorhombic chiral space group $\mathrm{P} 2{ }_{1} 2_{1} 2_{1}$. Its structure had been previously reported by Shoja (Acta Cryst. C45, 828, 1989) and Yamovoi et al. (Khim. Prir. Soedin (5), 361, 2001) in the centrosymmetric space groups Pbca and P21/c, respectively.
\end{abstract}

\section{INTRODUCTION}

High speed countercurrent chromatography (HSCCC) is a support-free liquid-liquid partition chromatographic technique which eliminates the problem of the adsorption of a sample onto a solid support and has been widely used for the purification of natural products, including flavanones ${ }^{1}$. In this work this fast technique has been applied in combination with medium pressure column chromatography for the purification of the phenolic constituents in an organic extract of aerial parts of Nolana ramossisima I.M. Johnst. (Solanaceae), an endemic species of Paposo Valley, Northern Chile.

The main compound isolated, 5-hydroxy-7-methoxy-2-phenylchroman4-one, synonym: pinostrobin is an important biologically active flavanone previously isolated from different plant materials. This flavanone is a constituent of Pinus strobus and many other pine species and, inter alia, Artemisia campestris, Boesenbergia pandurata, Boesenbergia rotunda, Sarcandra glabra, and Polygonum lapathifolium, and has been identified also in honey ${ }^{2}$, propolis ${ }^{3}$, and trees frequently visited by bees such as Alnus spp. and Populus spp. Pinostrobin has shown antileukemic ${ }^{4}$, antioxidant ${ }^{5}$ and antibacterial activity ${ }^{3}$ and inhibits TNF- $\boldsymbol{\alpha}$ and IL-1 $\boldsymbol{\beta}$ production ${ }^{6}$. Pinostrobin is an inducer of mammalian phase 2 chemoprotective and antioxidant enzymes ${ }^{2}$ and an inhibitor of DNA topoisomerase I activity ${ }^{7}$. In our hands the title compound crystallized as a new non-centrosymmetric polymorph. The existence of polymorphic forms provides a unique opportunity for the investigation of structure-property relationships, since by definition the only variable among polymorphs is that of crystal structure, and one of the most effective strategies for studying structure-property relationships has been to follow the behavior of a physical property through a polymorphic phase change.

\section{EXPERIMENTAL}

\section{General}

Nolana ramosissima was collected in Paposo, Antofagasta, Chile in September 2011. A voucher herbarium specimen is deposited in the laboratory of Natural Products, University of Antofagasta, with the number Nr 110403. Dried and finely powdered aerial parts of $N$. ramossisima $(1562 \mathrm{~g})$ were extracted with petroleum ether ( $2 \mathrm{~L}, 3$ times in the dark, $24 \mathrm{~h}$ each time). After evaporation of the solvent in vacuo at $35^{\circ} \mathrm{C}$, a dark gummy extract $(35 \mathrm{~g})$ was obtained. The extract $(20 \mathrm{~g})$ was submitted to medium pressure column chromatography (Silica Gel $60 \mathrm{H}, 7$ x $40 \mathrm{~cm}$ ) using n-hexane:ethyl acetate 9:1 as solvent system and 41 fractions of $50 \mathrm{~mL}$ each were collected. The fractions were combined according to their TLC analysis and 6 combined fractions were obtained. Fraction $4(483 \mathrm{mg})$ was re-chromatographed using a Quattro MK7 HSCCC instrument ${ }^{8}$ equipped with three preparative stainless steel coils of $115 \mathrm{~mL}$ each (2.10 mm I.D) and one SSI model Series II HPLC pump, using $\mathrm{n}$-hexane:ethyl acetate:acetonitrile 5:3:5 $\mathrm{v} / \mathrm{v} / \mathrm{v}$ as solvent system. The filtered sample solution $(5 \mathrm{~mL})$ was introduced into the preparative $(115 \mathrm{~mL})$ column through a manual low-pressure sample injection valve using a $5 \mathrm{~mL}$ sample loop. The lower phase was used as the mobile phase and was pumped at a flow rate of $4.0 \mathrm{~mL} / \mathrm{min}$ in the 'head-to-tail' mode. After the mobile phase front emerged and hydrodynamic equilibrium was established in the column, the percentage of the retention of the stationary phase was recorded. Fractions of about $1.0 \mathrm{~mL}$ were collected using a Gilson fraction collector. The spin rate of the planetary coils was set at $850 \mathrm{rpm}$ and the percentage of retention of the upper organic stationary phase was $72 \%$ at $25{ }^{\circ} \mathrm{C}$. From fractions $8-15$, compound I (5-hydroxy-7-methoxy-flavanone, $120 \mathrm{mg}$ ) was obtained after recrystallization from ethyl acetate:

Colourless crystals, m.p. $96-97{ }^{\circ} \mathrm{C}$. The molecular weight was determined by ESI-MS/MS with a mass spectrometer (HCT-Ultra ETD II, Bruker Daltonics, Germany) [M-H] : 269.27, $[\mathrm{M}+\mathrm{H}]^{+}: 271, \mathrm{MS}^{2}: 241.9,178.3,161.8$. 153.2. ${ }^{1} \mathrm{H}$ NMR $\left(300 \mathrm{MHz}, \mathrm{CDCl}_{3}\right) \delta \mathrm{ppm}: 5.44(1 \mathrm{H}, \mathrm{dd}, J=3.1$ and $16.1 \mathrm{~Hz})$, $3.80\left(\mathrm{~s}, \mathrm{OCH}_{3}\right), 3.12(1 \mathrm{H}, \mathrm{dd}, J=3.3$ and $12.9 \mathrm{~Hz}), 2.84(1 \mathrm{H}, \mathrm{dd}, J=10.2$ and $14.7 \mathrm{~Hz}), 6.10(1 \mathrm{H}, \mathrm{d}, J=2.3 \mathrm{~Hz}), 6.12(1 \mathrm{H}, \mathrm{d}, J=2.3 \mathrm{~Hz}), 7.47(5 \mathrm{H}, \mathrm{m}), 12.11$ $(1 \mathrm{H}, \mathrm{s}, \mathrm{OH}) .{ }^{13} \mathrm{C}$ NMR $\left(300 \mathrm{MHz}, \mathrm{CDCl}_{3}\right) \delta \mathrm{ppm}: 79.14(\mathrm{C}-2), 42.75(\mathrm{C}-3)$, 196.16 (C-4), 162.44 (C-5), 94.62 (C-6), 167.94 (C-7), 94.13 (C-8), 163.87 (C-9), 102.77 (C-10), 137.86 (C-1), 126.96 (C-2), 129.16 (C-3), 126.96 (C4), $129.16(\mathrm{C}-5), 126.96(\mathrm{C}-6) .{ }^{1} \mathrm{H}$ and ${ }^{13} \mathrm{C}$ NMR (Bruker Avance $300 \mathrm{MHz}$, $\mathrm{CDCl}_{3}$ ). These data, together with ESI-MS/MS and correlations observed in the HSQC and HMBC spectra, are consistent with the structure of 5-hydroxy7-methoxy-2-phenylchroman-4-one (pinostrobin, Figure 1) confirmed by comparison of spectroscopic data with those reported in the literature $\mathrm{e}^{4,9}$.

\section{Crystal structure determination}

Colorless block crystals of pinostrobin of approximate dimensions $0.1 \times 0.08 \times 0.4 \mathrm{~mm}$ were obtained by slow evaporation of a $\mathrm{MeOH}$ solution. A well-shaped and suitably-sized single crystal was selected for the X-ray diffraction structure determination experiment. The X-ray intensity data were collected at $293 \mathrm{~K}$ on an Enraf Nonius CAD4-MACH3 diffractometer, using MoK $\alpha$ graphite monochromatic radiation $((\lambda=0.71073 \AA)$. CAD4 software was used for data collection and cell refinement, and HELENA software of the WINGX program was used for data reduction. The structure was solved by direct methods using the SHELXS2013 program $^{12}$ and the refinement was carried out using SHELXL 2013 ${ }^{12}$. All non-hydrogen atoms of the molecule were clearly solved and full-matrix least-square refinement of these atoms with anisotropic thermal parameters was carried out. Hydrogen atoms on carbon and oxygen atom were positioned stereochemically and were refined with fixed individual displacement parameters [Uiso $(\mathrm{H})=1.5 \mathrm{Ueq}(\mathrm{C}$ or $\mathrm{O})$ for methyl and hydroxyl groups or 1.2 Ueq (C) for methine and methylene groups and the aromatic ring hydrogen atom] using a riding and rotating group model (for methyl and hydroxyl groups), with $\mathrm{C}-\mathrm{H}$ bond lengths of $0.96,0.97,0.98$ and $0.82 \AA$ for methyl, methine, methylene and hydroxyl groups, respectively. The hydrogen atom of the hydroxyl group was located by difference Fourier synthesis and was kept rigid together with its respective oxygen atom during the subsequent refinements. WINGX software was used to analyze and prepare the data for publication ${ }^{13}$. Molecular graphics were prepared using OLEX2 ${ }^{14}$ and Mercury ${ }^{16}$. Since the most electron-rich atom is the oxygen atom, which does not have a sufficiently large anomalous scattering (using MoKa radiation), it was not possible to determine the enantiomer present using the Flack method ${ }^{17}$. Table 1 summarizes the results. 
Table 1. Crystallographic data, details of data collection and structure refinement parameters for compound (II).

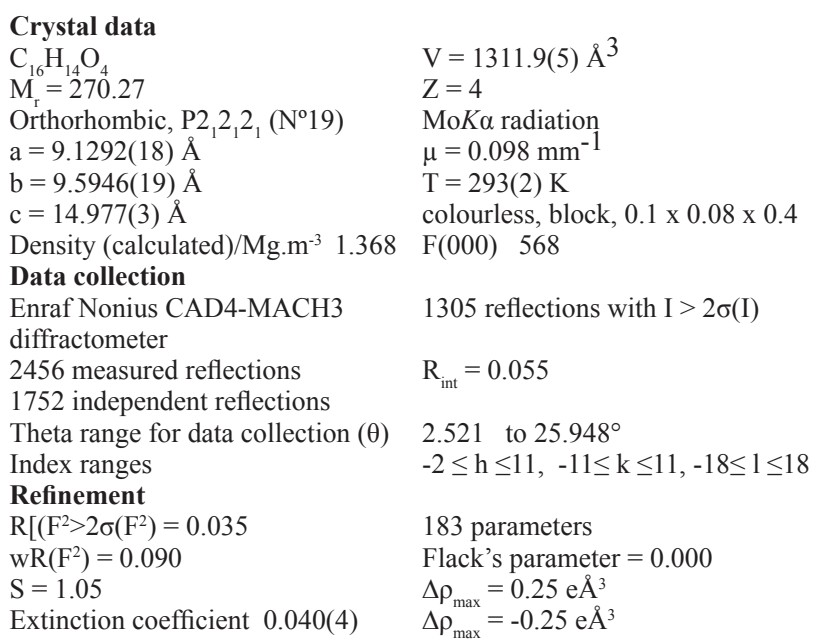

\section{RESULTS AND DISCUSSION}

The title compound (I) is a new polymorph of structures II and III reported by Shoja ${ }^{10}$ and by Yamovoi et al. ${ }^{11}$. In the Shoja report, the compound crystallized in the orthorhombic space group Pbca $Z=8$, cell parameters $a=$ $10.127(2) \AA, b=15.270(3) \AA, c=8.226(2) \AA, V=1270.9(5) \AA^{3}$, whereas the structure reported by Yamovoi et al. is in the monoclinic space group P21/c, $\mathrm{Z}=4, \mathrm{a}=10.172(2) \AA, \mathrm{b}=16.079(2) \AA, \mathrm{c}=8.079(3) \AA, \beta=91.74(1)^{\circ}, \mathrm{V}=$ $1320.756 \AA^{3}$. In our case compound I crystallized in the orthorhombic chiral space group $\mathrm{P}_{1} 2_{1} 2_{1}, \mathrm{Z}=4, \mathrm{a}=9.1292(18) \AA, \mathrm{b}=9.5946(19) \AA, \mathrm{c}=14.977(3)$ $\AA, \mathrm{V}=1311.9(5)$. In all three polymorphic forms, the tetrahydropyran ring has skew-boat conformation $\left(\mathrm{Q}_{\mathrm{T}}=0.455(6) \AA, \theta=123.1(7)^{\circ}, \varphi=249.0(8)^{\circ}\right.$ mean, for three polymorphs $)^{15}$ and the phenyl ring has an equatorial $\alpha$-orientation relative to the tetrahydropyran ring, Figure 1. In Figure 2 structures I and II) are superimposed in capped stick fashion. The overlay of molecular backbones clearly shows the conformational similarity between homologous atoms, except for the hydroxyl hydrogen atoms of the hydroxyphenyl group, where the $\mathrm{H}$ atoms point up and down in I and II, respectively. Another important difference between both structures is the orientation of the phenyl ring with respect to the plane defined by tetrahydropyran ring atoms O1-C8-C9-C10-C15 (RMSD $=0.043 \AA$ and $0.018 \AA$ for $\mathbf{I}$ and II, respectively), $85.56(15)^{\circ}$ vs. $109.4(3)^{\circ}$. Similarly, the main difference between I and III is the orientation of the phenyl ring with respect to the plane defined by O1-C8-C9-C10-C15 (RMSD $=0.043$ $\AA$ and $0.015 \AA$ for I and III, respectively), $85.56(15)^{\circ}$ vs. $38.5(3)^{\circ}$, Figure 3 . The bond angles and distances are normal and similar to those in structures II and III, Table 2. In the three polymorphs the molecular conformation is stabilized by one intramolecular hydrogen bond between the carbonyl $\mathrm{O}$ atom and the $\mathrm{H}$ atom of the hydroxyl group with graph-set motif $\mathrm{S}(6)^{18}$, but the geometry of this interaction is different for each polymorph $(\mathrm{H} 2 \mathrm{O} 2 \cdots \mathrm{O} 4=1.893(2) \AA$, $\mathrm{O} 2 \cdots \mathrm{O} 4=2.618(3) \AA, \mathrm{O} 2-\mathrm{H} 2 \cdots \mathrm{O} 4=146.84(18)^{\circ}$ for $\mathbf{I} ; \mathrm{H} 2 \mathrm{O} 2 \cdots \mathrm{O} 4=1.598(5)$ $\AA, \mathrm{O} 2 \cdots \mathrm{O} 4=2.574(7) \AA, \mathrm{O} 2-\mathrm{H} 2 \cdots \mathrm{O} 4=174.2(4)^{\circ}$ for II; $\mathrm{H} 2 \mathrm{O} 2 \cdots \mathrm{O} 4=1.79(6)$ $\AA, \mathrm{O} 2 \cdots \mathrm{O} 4=2.685(7) \AA, \mathrm{O} 2-\mathrm{H} 2 \cdots \mathrm{O} 4=160(6)^{\circ}$ for III).

\section{CONCLUSIONS}

The main conclusion of this work is that a new, non-centrosymmetric polymorph of 5-hydroxy-7-methoxy-2-phenylchroman-4-one (pinostrobin), was determined by X-ray methods, was isolated from an organic extract of aerial parts of Nolana ramossisima Johnst., an endemic species of the Paposo Valley, Northern Chile, using high speed countercurrent chromatography (HSCCC) and slow evaporation of a methanol solution.

\section{Supplementary material}

CCDC-1019211 contains the supplementary crystallographic data for this paper. These data can be obtained free of charge from the Cambridge Crystallographic Data Centre via www.ccdc.cam.as.uk/data_request/cif.
Table 2. Selected bond distances $(\AA)$ and angles $\left(^{\circ}\right)$ for polymorphs I, II and III.

\begin{tabular}{|c|c|c|c|}
\hline & I & II & III \\
\hline C9-O4 & $1.238(4)$ & $1.250(8)$ & $1.232(8)$ \\
\hline C11-O2 & $1.348(4)$ & $1.367(8)$ & $1.348(8)$ \\
\hline C7-O1 & $1.448(3)$ & $1.450(8)$ & $1.441(7)$ \\
\hline C15-O1 & $1.371(3)$ & $1.369(7)$ & $1.400(7)$ \\
\hline C13-O3 & $1.360(3)$ & $1.363(8)$ & $1.406(7)$ \\
\hline O3-C16 & $1.426(4)$ & $1.416(9)$ & $1.400(8)$ \\
\hline C7-C1 & $1.448(3$ & $1.450(8)$ & $1.441(7)$ \\
\hline & & Angles & \\
\hline C15-O1-C7 & $115.3(2)$ & $114.1(5)$ & $119.1(5)$ \\
\hline C13-O3-C16 & $117.8(2)$ & $119.3(6)$ & $116.4(5)$ \\
\hline C10-C11-O2 & $120.2(3$ & $119.2(6)$ & $119.9(5)$ \\
\hline
\end{tabular}

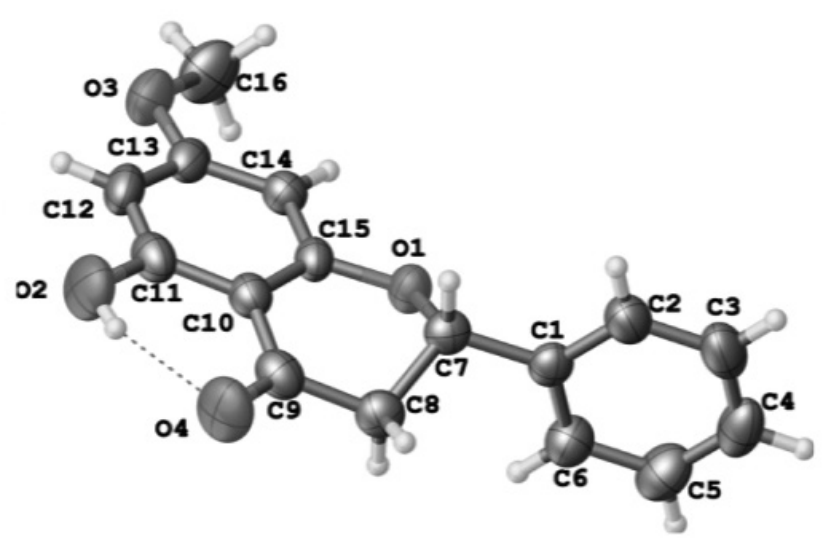

Figure1. Molecular structure of $\mathbf{I}$ with the atom numbering scheme. The thermal ellipsoids are drawn at $40 \%$ probability level.

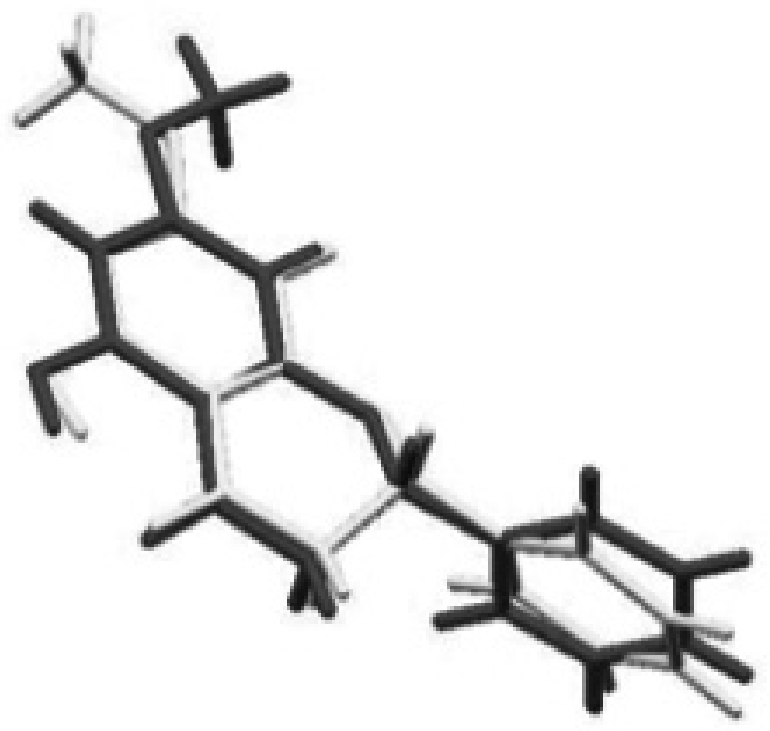

Figure 2: Superimposed structures for the title compound (red) and polymorph II (Yellow). 


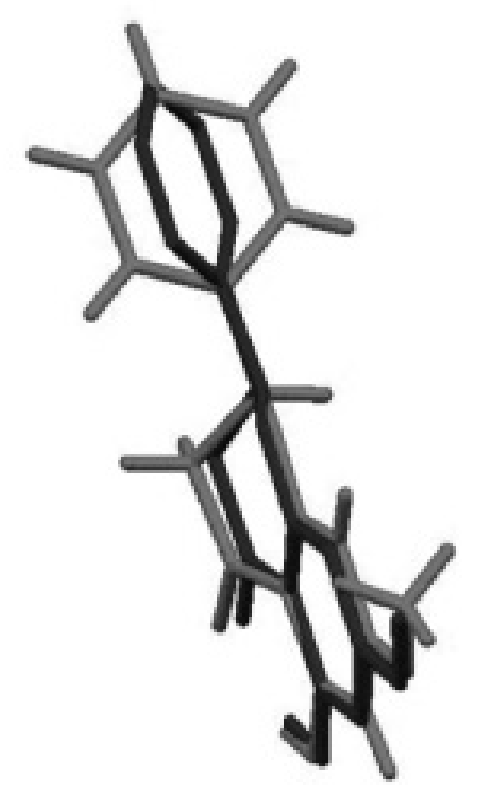

Figure 3: Superimposed structures for the title compound (red) and polymorph III (blue).

\section{ACKNOWLEDGEMENTS}

The authors thank FONDECYT (Chile) (Grant 1140178) for financial support.

\section{REFERENCES}

1. J. Zhang, C. Sun, Y. Yan, Q. Chen, F. Luo, X. Zhu, X. Li, K. Chen, Food Chem. 135, 1471-1478 (2012)

2. J. W. Fahey, K. K. Stephenson, J. Agric. Food Chem. 50, 7472-7476 (2002)

3. C. F. Massaro, M. Katouli, T. Grkovic, H. Vu, R. J. Quinn, T. A. Heard, C. Carvalho, M. Manley-Harris, H. M. Wallace, P. Brooks, Fitoterapia 95, 247-257 (2014)

4. H. D. Smolarz, E. Mendyk, A. Bogucka-Kocka, J. Kocki, Z. Naturforsch. C61, 64-68 (2006)

5. T. Sudsai, S. Prabpai, P. Kongsaeree, C. Wattanapiromsakul, S. Tewtrakul, J. Ethnopharm. 154, 453-461 (2014)

6. N. K. Patel, K. K. Bhutani, Phytomedicine 21, 946-953 (2014)

7. T. R. L. Siekmann, K. M. Burgazli, M. A. Bobrich, G. Nöll, A. Erdogan, Eur. Rev. Med. Pharmacol. Sci. 17, 668-672 (2013)

8. M. J. Simirgiotis, G. Schmeda-Hirschmann, J. Bórquez, E. J. Kennelly, Molecules 18, 1672-1692 (2013)

9. P. K. Agrawal, Carbon-13 NMR of flavonoids. Elsevier: Michigan p 564. 1989

10. M. Shoja, Acta Cryst. C45, 828-829 (1989)

11. V.I. Yamovoi, E.A. Kul'magambetova, A.T. Kulyyasov, K.M. Turdybekov, S.M. Adekenov. Khim. Prir. Soedin (5), 361-363 (2001) Chem. Nat. Compd. 37 (5), 424-427, (2001).

12. G.M. Sheldrick, Acta Crystallogr. A64, 112-122 (2008)

13. L.J. Farrugia, J. Appl. Crystallogr. 32, 837 (1999)

14. O.V. Dolomanov, L.J. Bourhis, R.J. Gildea, J.A.K. Howard, H. Puschmann, J. Appl. Cryst. 42, 339-341(2009)

15. D. Cremer, J. A. Pople, J. Am. Chem. Soc. 97, 1354-1358 (1975)

16. C.F. Macrae, I.J. Bruno, J.A. Chisholm, P.R. Edgington, P. McCabe, E. Pidcock, L. Rodriguez-Monge, R. Taylor, J. van de Streek, P.A. Wood, $J$. Appl. Cryst. 41, 466-470 (2008)

17. H.D. Flack, Acta Cryst. A39, 876-881 (1983)

18. J. Bernstein, R.E. Davis, L. Shimoni, N.-L. Chang. Angew. Chem. Int. Ed. Engl. 34, 1555-1573 (1995) 